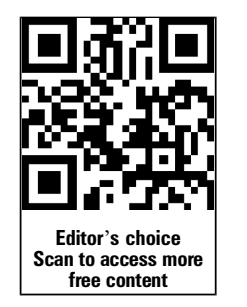

${ }^{1}$ Centre for Kidney Disease Research, School of Medicine, The University of Queensland, Translational Research Institute, Brisbane, Australia ${ }^{2}$ Department of Urology, Princess Alexandra Hospital, Brisbane, Australia ${ }^{3}$ Department of Surgery, Faculty of Medicine, University of Malaya, Kuala Lumpur, Malaysia

${ }^{4}$ University Malaya Cancer Research Institute, Kuala Lumpur, Malaysia

${ }^{5}$ Aquesta Pathology, Brisbane, Australia

\section{Correspondence to} A/Professor Glenda Gobe, Centre for Kidney Disease Research, School of Medicine, Translational Research Institute, Kent Street, Woolloongabba, Brisbane 4102, Australia; g.gobe@uq.edu.au

Received 1 August 2013 Revised 30 September 2013 Accepted 1 October 2013 Published Online First 29 October 2013

\footnotetext{
To cite: $\mathrm{Ng} \mathrm{KL}$, Rajandram R, Morais $\mathrm{C}$, et al. J Clin Pathol 2014;67:97-104.
}

\title{
Differentiation of oncocytoma from chromophobe renal cell carcinoma (RCC): can novel molecular biomarkers help solve an old problem?
}

\author{
Keng Lim Ng, ${ }^{1,2,3}$ Retnagowri Rajandram, ${ }^{1,3,4}$ Christudas Morais, ${ }^{1}$ Ning Yi Yap, ${ }^{3}$ \\ Hema Samaratunga, ${ }^{5}$ Glenda C Gobe, ${ }^{1}$ Simon T Wood ${ }^{2}$
}

\begin{abstract}
Standard treatment of renal neoplasms remains surgical resection, and nephrectomy for localised renal cell carcinoma (RCC) still has the best chance of cure with excellent long-term results. For smaller renal masses, especially stage T1a tumours less than $4 \mathrm{~cm}$, nephronsparing surgery is often employed. However, small incidentally detected renal masses pose an important diagnostic dilemma as a proportion of them may be benign and could be managed conservatively. Renal oncocytoma is one such lesion that may pose little risk to a patient if managed with routine surveillance rather than surgery. Additionally, lower-risk RCC, such as small chromophobe RCC, may be managed in a similar way, although with more caution than the renal oncocytomas (RO). The ability to differentiate ROs from chromophobe RCCs, and from other RCCs with a greater chance of metastasis, would guide the physician and patient towards the most appropriate management, whether nephron-sparing surgical resection or conservative surveillance. Consistent accurate diagnosis of ROs is likely to remain elusive until modern molecular biomarkers are identified and applied routinely. This review focuses on the differentiation of renal oncocytomas and chromophobe RCCs. It summarises the history, epidemiology and clinical presentation of the renal neoplasms, explains the diagnostic dilemma, and describes the value, or not, of current molecular markers that are in development to assist in diagnosis of the renal neoplasms.
\end{abstract}

\section{INTRODUCTION}

The incidence of renal tumours has been increasing steadily in Europe, USA and Australia over the past three decades. ${ }^{1}$ The widespread use of crosssectional imaging has increased the detection of incidental smaller tumours, ${ }^{2}$ while the 20-30\% incidence of advanced tumours has remained relatively constant. ${ }^{3}$ Despite current imaging techniques and the availability of renal lesion biopsy, most contemporary surgical series continue to report significant rates of benign lesions among resected small renal masses. ${ }^{2} 4$ Preoperative biopsy of these small lesions is not widely employed, and one contributing factor is potential diagnostic uncertainty in the differentiation of benign renal oncocytomas (RO) from malignant chromophobe renal cell carcinomas (chRCC) ${ }^{5}$ and, as an added difficulty, eosinophilic clear-cell RCCs (ccRCC). Consequently, there is a group of small renal lesions where increased confidence in characterisation may defer or obviate the need for surgical intervention. ROs and small chRCCs are two such lesions.

ChRCCs, although having a more favourable prognosis than other RCC subtypes, is a malignant tumour with the potential for metastatic spread and death. By comparison, there appears to be only one confirmed case report of metastases from ROs. ${ }^{6}$ Thus, due to its benign nature, ROs can usually be monitored and treated expectantly. Similarly, small renal masses found to be chRCCs may, in some situations, be suitable for active surveillance rather than immediate resection or ablation. ROs and chRCCs are often considered to be extremities of the same morphological spectrum. ${ }^{7}$ Proper differentiation largely relies on $\mathrm{H} \& \mathrm{E}$ histochemistry of sections, and an experienced histopathologist to discern the characteristic histomorphologic features between the two entities. Immunohistochemistry is used in selected instances. Electron microscopy was commonly performed in the past, but is done only in rare cases now, given the prominent overlap of staining patterns. There is also the coexistence of ROs with chRCCs seen in sporadic cases of hybrid tumours, renal oncocytosis and Birt-Hogg-Dube (BHD) syndrome. Differentiation of ROs and chRCCs, especially as small renal masses, from other more sinister forms of RCCs, like ccRCCs, is also important for the appropriate management of these patients.

\section{HISTORY}

RO was first described by Zippel in 1942 as a neoplasm entirely composed of large eosinophilic cells called oncocytes. ${ }^{8}$ Later, in 1976, Klein and Valensi ${ }^{9}$ identified another 13 cases as a distinct clinical pathological entity with a typical benign histological presentation and clinical course. RO was originally thought to derive from renal proximal tubules, but most pathologists now suggest a distal origin, ${ }^{10}$ most likely arising from intercalated cells of collecting ducts. The first description of chRCCs, as distinct from ccRCCs, was made by Theones et al in $1985,{ }^{11}$ and a year later, they added the chRCC subtype to the classification of renal tumours. ${ }^{12}$ The cell characteristic had been described prior to the 1985 publication but only in experimentally induced adenomas in animals. The chromophobe cells had slightly opaque or finely reticular cytoplasm that resisted staining with haematoxylin and eosin. They were able to be distinguished from ccRCCs by a strongly positive reaction within their cytoplasm to Hale's colloidal iron, and a weaker positive reaction with Alcian Blue, a 
distinction that has since been found to be unreliable. The authors, however, made a step forward for classification of RCCs by suggesting that the descriptive term 'light cell' RCC should be discarded and replaced by either 'clear cell' or 'chromophobe cell' as appropriate. They pointed out that chromophobe cell tumours were likely to have a different derivation from ccRCCs and other RCCs, and that they may also have a different prognosis, a fact that has since been established. Since the description of chRCCs came a decade later than ROs, there were many instances in that era where renal tumours, which were likely to be chRCCs, were described as ROs. This may have contributed to the confusion surrounding the original recognition of the benign nature of ROs.

\section{EPIDEMIOLOGY}

Renal tumours are highly heterogeneous with at least 16 known subtypes, of which four subtypes predominate. ${ }^{13}{ }^{14}$ CcRCCs, arising from the proximal tubular epithelial cells, is the most common subtype constituting $70-80 \%$ of RCCs, followed by papillary (10-15\%), chRCCs (5\%) and collecting duct RCCs $(<1 \%) .{ }^{15}{ }^{16} \mathrm{RO}$ accounts for approximately $3-7 \%$ of all adult renal neoplasms. The peak age of incidence for detection of ROs tends to be in the seventh decade of life. For chRCCs, the peak incidence occurs in the sixth decade. For cases of RO, men seem to be affected twice as often as women. For chRCCs, the disease tends to affect men and women equally. ${ }^{17}$

ROs and chRCCs can develop as either sporadic or familial forms, and both can be associated with distinct genetic mutations. The majority of ROs and chRCCs occur as sporadic cases. $^{18} 19$ There is also the occasional occurrence of familial renal cancers of oncocytoma with BHD syndrome. Familial oncocytoma is due to partial or complete loss of multiple chromosomes. BHD syndrome is an autosomal dominant inherited syndrome with the BHD gene locus located in the short arm of chromosome $17 .^{20} 21$ This syndrome is characterised by fibrofolliculomas, lung cysts that can lead to spontaneous pneumothoraxes, and various subtypes of renal tumours including hybrid tumours, ROs, chRCCs and ccRCCs.

Sometimes in rare instances, patients can present with renal oncocytosis. Renal oncocytosis was first described in $1982^{22}$ : multiple and bilateral oncocytic nodules and a spectrum of oncocytic changes are found diffusely throughout the renal parenchyma. A large series investigating renal oncocytosis revealed that hybrid development of ROs and chRCCs was most common. $^{23}$

\section{CLINICAL PRESENTATION}

Generally, patients with ROs tend to be asymptomatic and present incidentally following cross-sectional imaging for an unrelated complaint. Similarly, the majority of patients with chRCCs present incidentally with asymptomatic renal masses. ${ }^{24}$ Less commonly, chRCCs may present with local symptoms of haematuria, flank mass and loin pain, and constitutional symptoms of weight loss and loss of appetite. ${ }^{18}$ chRCCs Can also present with paraneoplastic syndrome and metastases with predilection to the liver. ${ }^{25}$ In the largest published series to date, chRCCs present with metastases at a rate of $1.3 \% .{ }^{24}$ Generally, patients with chRCCs tend to present in less advanced stages (I and II), less frequently with metastases and are usually of better performance status ${ }^{25}$ compared with other subtypes of RCCs. It should be noted, however, that the local and constitutional symptoms for chRCCs are similar to those seen for other RCCs.
ROs will almost always follow a benign clinical course with no significant risk of metastases, whereas malignant chRCCs can subsequently progress to metastases. There have been a few isolated case reports of metastatic ROs on initial presentation or following resection of the ROs, ${ }^{13} 26$ however, these case reports have not been substantiated with proper histopathological confirmation of the metastatic deposits, except for one liver metastasis. $^{6}$ Therefore, the distinction of almost exclusively benign ROs from malignant, potentially metastatic, chRCCs is needed to guide the management of these often difficult-to-separate entities.

Renal tumours can be detected by radiological imaging using ultrasonography, CT, MRI and positron emission tomography (PET). Usually, following the suspicion of a renal mass, either clinically or via ultrasound, a 4-phase CT scan will be performed to delineate its nature. Multiphase CT scans can clearly delineate the renal tumour, its local extension to surrounding tissues and detect any metastases to regional lymph nodes or other organs. Cases of small renal masses (lesions $<4 \mathrm{~cm}$ ) detected incidentally are increasing in incidence largely owing to the widespread use of ultrasound and CT scans. Generally, there is no accurate differentiation between benign and malignant renal lesions using CT scans (except angiomyolipoma), but retrospectively, about $20 \%$ of these small renal masses will be found to be benign lesions. Percutaneous biopsy of these small renal masses provides an enticing strategy to identify lesions of no or low malignant

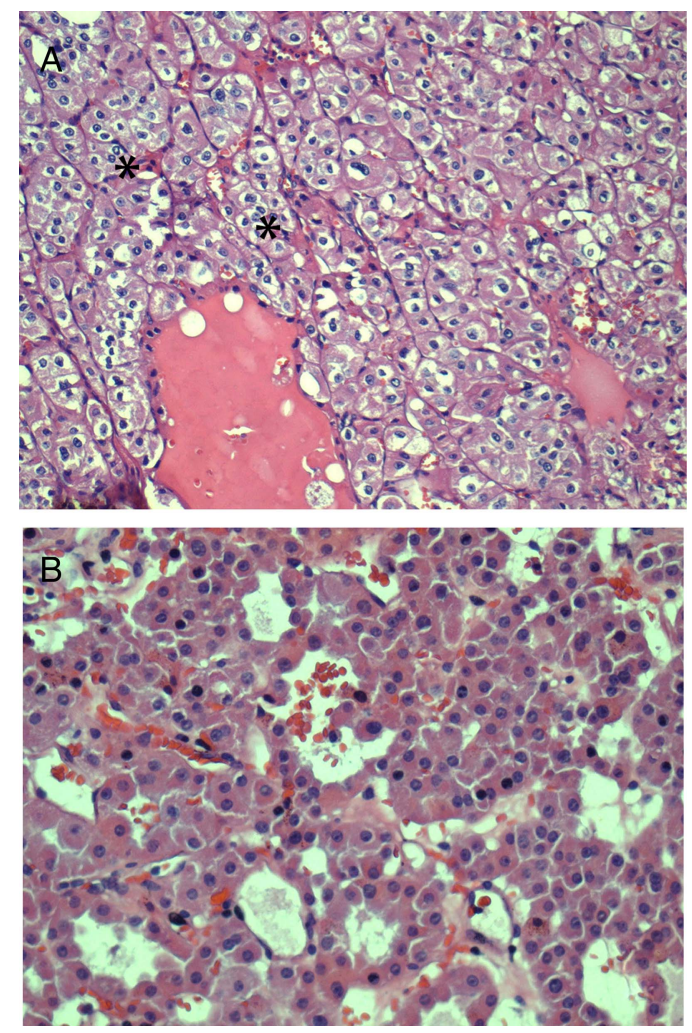

Figure 1 (A) H\&E-stained section of an example of eosinophilic variant of chromophobe renal cell carcinoma, showing typical large, pale, polygonal cells with prominent cell membranes. Nuclei tend to be irregular and wrinkled, and cells are sometimes binucleated (asterisks). Perinuclear clearing can be prominent. (B) H\&E stained section of an example of renal oncocytoma, showing large oncocytes with densely granular eosinophilic cytoplasm. Cells are round to polygonal and nuclei are round and monotonous. Nucleoli are small and inconspicuous. 
Table 1 Comparison of macroscopic, microscopic and ultrastructural features for oncocytoma and chromophobe renal cell carcinoma

\begin{tabular}{|c|c|c|}
\hline Features & Oncocytoma & Chromophobe RCC \\
\hline Macroscopic & $\begin{array}{l}\text { Well circumscribed, tan or } \\
\text { mahogany brown, sometimes } \\
\text { with a central stellate scar }\end{array}$ & $\begin{array}{l}\text { Usually circumscribed, } \\
\text { homogenous, light brown, } \\
\text { beige, yellow or tan colour. }{ }^{46}\end{array}$ \\
\hline $\begin{array}{l}\text { Microscopic } \\
\text { Cytoplasm } \\
\text { Nuclei }\end{array}$ & $\begin{array}{l}\text { Cells arranged in a nested or } \\
\text { organoid pattern, but tubular, } \\
\text { trabecular or solid structure } \\
\text { can also be seen. }{ }^{54} \\
\text { Granular eosinophilic } \\
\text { cytoplasm } \\
\text { Round, uniform nuclei }{ }^{55}\end{array}$ & $\begin{array}{l}\text { Variants: classic, eosinophilic } \\
\text { and mixed. } \\
\text { Cells arranged in sheets, with } \\
\text { distinct or accentuated cell } \\
\text { borders. }^{56} \\
\text { Granular eosinophilic } \\
\text { (eosinophilic variant) or pale, } \\
\text { reticular and almost transparent } \\
\text { appearance (classic). } .^{57} \\
\text { Presence of perinuclear halos, } \\
\text { wrinkled nuclei. }{ }^{57}\end{array}$ \\
\hline Ultrastructural & $\begin{array}{l}\text { Abundant mitochondria with } \\
\text { lamellar or focally stacked } \\
\text { cristae. Absent or sparse } \\
\text { vesicles. }{ }^{55}\end{array}$ & $\begin{array}{l}\text { Scant mitochondria with } \\
\text { tubule-vesicular cristae. } \\
\text { Abundant microvesicles } \\
\text { between mitochondria. }^{46}\end{array}$ \\
\hline
\end{tabular}

potential, however, widespread uptake of biopsy into clinical practice has been limited.

Predicting whether a small renal mass is malignant, based on its growth velocity, has been reported, but there is no good correlation of malignancy with growth rate. ${ }^{16} \mathrm{~A}$ recent meta-analysis of small renal masses which included benign and malignant lesions, showed a mean growth rate of $0.28 \mathrm{~cm}$ annually (range 0.09 to 0.86 ) for small renal masses followed with imaging. ${ }^{14}$ ROs increase in size with variable velocity, with one case series reporting an observed growth rate of $0.20 \mathrm{~cm}$ annually. ${ }^{15}$ The largest pool of 33 biopsy-proven benign ROs demonstrated a growth rate similar to reported growth rates for RCCs, thus highlighting again that observation of growth cannot distinguish between the benign or malignant nature of such lesions. ${ }^{16}$ The locality and size of tumours may also be variable. Uncommonly, there have been case reports of large ROs $(25 \times 15 \times 12 \mathrm{~cm}),{ }^{27}$ but the average size is normally around 4.9 $\pm 2.7 \mathrm{~cm} .{ }^{28}$ Published reports worldwide show that ROs can be multifocal in $6-11 \%,{ }^{29} 30$ and bilaterality was reported in about $3-5 \% .{ }^{29}{ }^{31}$ By comparison, the median size of chRCCs is about $6.0 \mathrm{~cm},{ }^{18}$ which is larger compared with other subtypes of RCCs. $^{32}$ Multifocality of chRCCs is usually around $10-12 \% .^{33}$

\section{DIAGNOSTIC DILEMMA}

The increasing use of CT scans for small renal masses has led to a diagnostic dilemma of accurately characterising the nature of these renal lesions and their subsequent management. Typically, on CT scans, RCCs are solid heterogeneous masses with contrast enhancement showing areas of patchy uptake of contrast. Locally advanced tumours may directly invade the adrenal gland, renal vein, inferior vena cava and regional lymph nodes. ChRCCs usually demonstrate homogeneous enhancement, whereas ccRCCs, papillary and collecting duct RCCs tended to show heterogeneous or predominantly peripheral enhancement. Calcification was seen more commonly in chRCCs than in

Table 2 Histochemistry and immunohistochemistry (IHC) to differentiate chromophobe renal cell carcinomas (RCC) and renal oncocytomas

\begin{tabular}{lll}
\hline Method & Number of patients & Success as biomarker \\
\hline $\begin{array}{l}\text { Hale's colloidal iron stain } \\
\text { Modified Mowry's colloidal iron } \\
\text { stain better characterised chRCC }\end{array}$ & 28 cases (11 chRCC, 12 RO, 6 cCRCC) & $\begin{array}{l}\text { Colloidal iron was diffusely and strongly positive in 9/11 of chRCC, focally and } 58 \\
\text { weakly positive in 5/12 of RO, and negative in all granular cell variants of } \\
\text { CCRCC (0/6). }\end{array}$
\end{tabular}

62 cases (14 chRCC, 19 RO, 11 ccRCC, 7 Positive colloidal iron stain was not limited to chRCC, however a diffuse and eosinophilic variants of $\mathrm{PRCC}$ ) strong, reticular staining pattern was observed only in chRCC $(100 \%)$. Staining patterns less consistent in all other renal neoplasms. Most RO (84\%) had focal, weak, fine dust-like positivity. 100\% ccRCC had focal, coarse, droplet-like positivity.

76 cases $(30$ ccRCC, 16 pRCC, 21 ChRCC, 8 RO, 1 cdRCC)

\section{CD10}

Outcome of CD10 to distinguish between chRCC and ROs is variable.

76 cases ( 30 ccRCC, 16 pRCC, 21 chRCC, 8 RO, 1 (dRCC)

83 cases (22 chRCC, 17 RO, and 45 CCRCC)

28 cases (11 chRCC, 12 RO, 6 ccRCC)
RCC marker (RCCma) RCCma is a relatively new IHC marker that has variable results.

76 cases $(30$ ccRCC, 16 pRCC, 21 chRCC, 8 RO, 1 cdRCC)

Renal cell neoplasm TMA (30 RO, 18 chRCC, 64 cCRCC, 50 pRCCs, 31 RO) 328 samples (256 ccRCC, 27 pRCC, 28 chRCC, 5 cdRCC, 5 unclassified RCC, 7 $\mathrm{RO})$

29 cases (11 chRCC, 12 RO, 6 ccRCC)

Vimentin
76 cases ( 30 ccRCC, 16 pRCC, 21

chRCC, 8 RO, 1 (dRCC)

83 cases (22 chRCC, 17 RO, 45 ccRCC)

Renal cell neoplasm TMAs (30 RO, 18 chRCC, 64 ccRCC, 50 pRCC, 31 RO)

Fine reticular cytoplasmic pattern with perinuclear halo $(87.5 \%$ chRCC; $16 \%$ ccRCC). $12.5 \%$ RO had focal, coarse, cytoplasmic staining without perinuclear halo.

CD10 positive, $79 \%$ cCRCC, $6.3 \%$ chRCC and $0 \%$ RO. CD10 reactivity favours cCRCC, and the absence of CD10 in RO shows CD10 could differentiate between chRCCs and RO in a panel of biomarkers.

CD10 positive, ccRCC (91\%), chRCC (45\%) and RO (29\%).

CD10 positive, $100 \%$ ccRCC, $72 \%$ chRCC and $58 \%$ RO. Not useful as a biomarker.

RCCma, positive in $62.5 \%$ ccRCC, $12.5 \% \mathrm{RO}$, but negative in chRCC. Holds potential as part of a panel to differentiate between ChRCC and RO.

RCCma, positive in most RCC with granular/eosinophilic features. cCRCC $(71 \%), \quad 60$ pRCC $(76 \%)$, negative in RO.

RCCma was negative in chRCC but was positive in 3/7 RO.

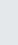


Table 3 Biomarkers used to differentiate chromophobe renal cell carcinoma (RCC) (chRCC) from oncocytoma (RO)

\begin{tabular}{ll}
\hline Method & Number of patients \\
\hline BCA2 & 158 patients (104 ccRCC, 8 chRCC, 2 pRCC, 38 \\
& RO, 6 oncocytic neoplasms \\
C-kit (encodes the & mRNA levels, 17 chRCC, 20 RO from cDNA \\
membrane-bound tyrosine & microarrays \\
kinase KIT) & IHC analysis, 226 renal tumours in TMAs (40 \\
& chRCC, 41 RO, 40 ccRCC, 29 renal \\
& angio-myolipoma, 21 pRCC). \\
EMA & 86 retrospective nephrectomy specimens (15 \\
& ccRCCs, 15 pRCCs, 15 chRCCs, 10 ROs, 6 cdc)
\end{tabular}

Significance of success as biomarker

Reference

All RO and oncocytic neoplasms, which favour RO, were positive for BCA2 50 while all RCC were negative, including chRCC.

Significant increment of c-kit mRNA and overexpression of KIT protein by 62 $\mathrm{IHC}$ in chRCC and RO, hence low potential for differentiating between the two types. However, there was potential for differentiating chRCC/RO from the other renal cell tumours (ccRCC and pRCC).

EMA was positive in chRCC (75-100\%), ccRCC (50-77\%) and oncocytomas $(51-86 \%)$, showing no major promise as a marker. (Comparison made with

3 tubulocystic carcinoma, 3 renal medullary carcinoma, 3 mucinous tubular and spindle cell carcinoma, 4 metanephric adenoma, 12 invasive high-grade urothelial carcinoma)

76 cases (30 ccRCC, 16 pRCC, 21 chRCC, 8 RO, 1 EMA was positive in $100 \%$ of ChRCCs, $100 \%$ of ROs and $75 \%$ of ccRCC. cdc)

So, we concluded that EMA is not a good marker for the differentiation of renal tumours.

Carbonic anhydrase IX (CA IX) TMAs, 20 cases of each cCRCC, chRCC, pRCC and RO

CA IX was highly sensitive for ccRCCs ( $90 \%$ positivity) and was negative in all other renal epithelial tumours except for 1 chRCC.

Galectin-3

TMAs, 20 cases of each $c$ RCC, chRCC, pRCC and RO

Galectin-3 found mostly in renal tumours with oncocytic features, including RO (100\%) and chRCCs (89\%). May hold small promise to distinguish these from other RCC.

Glutatione S-transferase alpha 22 chRCC, 17 RO, 45 ccRCC

$(\mathrm{GST}-\alpha)$

KIT (CD117)

256 ccRCC, 29 chRCC, 25 pRCC, 6cdc, 6 unclassified RCC, 7 RO, 20 UC, 7 NB, 2 AM

GST- $\alpha$ exclusively observed in ccRCCs.

$83 \%$ chRCCs and $71 \%$ RO had membranous immunoreactivity for KIT, while none of the other RCC or the angiomyolipomas expressed. Cannot be used to differentiate chRCC and RO.

11 chRCCs, 12 RO, 6 cCRCC

KIT was a very sensitive marker for both chRCC and RO, but not useful to 58 differentiate between the two. KIT with RCCma may be useful when trying to differentiate cCRCCs from chRCCs or ROs.

22 chRCC, RO \& ccRCC

CD15

10 ccRCC, pRCC, chRCC and RO

MAGE-A3/4 cancer testis antigen/CTA

RON proto-oncogene, encoding a receptor tyrosine kinase,

35 patients (17 RO, 18 chRCC)

TMAs ( 55 RO, 52 chRCCs). 15 \& 5 conventional sections of RO \& chRCC were also analysed 11 chRCC, 12 RO, 6 cCRCCs

35 patients ( $17 \mathrm{RO}, 18 \mathrm{chRCC}$ )

NY-ESO-1 CTA

Interphase fluorescence in situ hybridisation (FISH)

11 chRCC, 12 RO, compared with conventional metaphase cytogenetics by karyotyping.

Endogenous avidin-binding activity (EABA)
Renal TMAs (30 RO, 18 chRCC, 64 ccRCC, 50 pRCC, 31 benign renal tissues)

CD117, strongly expressed in chRCC $(82 \%)$ and RO (100\%), whereas none of the $\mathrm{CCRCCs}$ were immunoreactive.

CD15 was able to distinguish between chRCCs and RO. 7/10 RO (70\%) stained positive for CD15 and none of the chRCC stained for CD15. $88 \%$ RO stained positively for MAGE-A3/4; 39\% chRCC stained positively

69 of 70 RO and 55 of 57 chRCC had strong, diffuse cytoplasmic stain.

$11 / 11$ chRCCs, $12 / 12$ RO, but only $3 / 6$ of $\mathrm{CCRCC}$.

15/17 RO stained positive, and 6/18 chRCC were positive.

RO often show normal DNA content by interphase and metaphase analyses. The loss of 2 or more of chromosomes $1,2,6,10$, and 17 favours the diagnosis of chRCC over RO. FISH analysis is shown to be a useful tool that helps identify differences between these 2 tumour types. $97 \%$ RO, 26\% ccRCC, 35\% pRCC with granular/eosinophilic (GE) features and $6 \%$ of ChRCCs positive for EABA. RCC without GE features were negative. $E A B A$ is an excellent marker for $\mathrm{RO}$, and so useful in differentiating RO from chRCC.

Expression of PAX8 more frequent in RO than in chRCC (55\% vs $25 \%$ ). MUC1 expressed more diffusely and frequently in chRCC than RO $(94 \%$ vs $55 \%$ ).

papillary or conventional RCCs. ${ }^{34}$ On MRI, chRCCs typically have heterogeneous T2 signal intensity and enhancement.

By contrast, on CT scanning, ROs typically show a welldefined, smooth, relatively homogeneous solid mass with a central area of hypoattenuation due to the presence of a central stellate scar, and rarely show any extension to the renal vein, inferior vena cava or the adrenals. MRI scan will typically reveal low to moderate homogeneous intensity on T1-weighted images and relatively high signal intensity on T2-weighted images. ${ }^{35}$ Classically, if renal angiography on ROs were performed, it would show a typical spoke-wheel pattern, highlighting the marked peripheral vascularity in contrast with the relatively hypovascular central part of the tumour. However, classical hypoattenuation of the central stellate scar on CT scan is seen in less than one-third of ROs, and although characteristic of ROs, it is not diagnostic. ${ }^{1420}$ Moreover, there are no consistently reliable pathognomic CT scan features that can safely differentiate ROs from RCCs. ${ }^{36}$ Therefore, most ROs are treated as suspicious of RCCs based on imaging, and thereafter, are subjected to surgical resection.

A recent study on the ability of MRI to discriminate ROs from chRCCs showed that these two entities exhibited similar findings, and no MRI features were reliable in distinguishing between the two. ${ }^{37}$ The ability of any renal lesion to uptake the 18-fluorodeoxyglucose (FDG) is the basis of 18-FDG PET/CT scans. However, in detection of renal tumours, the role of FDG 
PET is limited as there are high false negative rates ${ }^{38}$ Benign ROs are also often FDG-avid, and thus, this cannot be used in separating them from malignant renal tumours. ${ }^{39}$ Recently, multiphasic multidetector CT scans have helped to discriminate ccRCCs from ROs, papillary RCCs and chRCCs, by using the different enhancements at various phases of the scans. ${ }^{40}$ This will aid somewhat in the distinction of ccRCCs from ROs, but not the discrimination of ROs from chRCCs. Arterial phase enhancements $>500 \%$ and washout values $>50 \%$ in Hounsfield units obtained in multiphasic CT scans can be seen exclusively in ROs and can aid in distinguishing ROs from other subtypes of RCCs. ${ }^{41}$

\section{PATHOLOGY}

Despite the non-invasive discriminatory features of multiphasic CT scans, renal mass biopsy provides the best opportunity for preoperative diagnosis. However, there are numerous potential shortcomings for this procedure, leading to the inevitability of surgical excision. One of the main drawbacks of renal mass biopsy is the relative difficulty faced by pathologists to accurately and conclusively diagnose renal tumour subtype from the limited tissue biopsy samples, as usually an entire range of cytoarchitectural features is necessary for examination to arrive at a diagnosis. ${ }^{42}$ However, as a general rule, if the lesion looks like chRCCs on needle biopsy, it can be confidently reported as such. By comparison, a lesion that looks like an RO may be incompletely sampled, with other areas merging into the eosinophilic variant of chRCCs. This may be a hybrid tumour or simply oncocytoma-like areas in a chRCC. Therefore, most pathologists would not diagnose an RO outright on a needle biopsy, and make a comment as to the possibility of having chRCCs elsewhere in the tumour. In addition to the difficulties in differentiating ROs from chRCCs clinically, the pathological features following surgical resection of these tumours often overlap and pose a diagnostic challenge to pathologists.

ChRCCs are well-circumscribed encapsulated tumours which have a light-brown to tan cut surface. These are typically solid but cystic areas can be found. Central scarring may be seen. Histologically, there are two types. The classic type has large polygonal cells with finely granular cytoplasm. These have prominent plant-like thick cell membranes. The eosinophilic variant is composed of polygonal cells with abundant eosinophilic cytoplasm. Nuclei are irregular, crinkled and angulated, often with perinuclear clearing. Binucleation is common. A solid sheet-like pattern with poor cellular cohesion is commonly found. ROs are also well circumscribed, but unencapsulated tumours which are typically mahogany brown but sometimes tan coloured. A central stellate scar is present in about one-third of cases. Rarely, cystic change or haemorrhage can be found. Histologically, there are large round polygonal cells with abundant eosinophilic cytoplasm and round nuclei. Nucleoli are inconspicuous. Cells form nests, tubules, acini and microcysts. Focal degenerative nuclear atypia may be seen. Figure 1 demonstrates histopathology of chRCCs and ROs.

Hybrid tumours have zones classic for ROs and chRCCs as described above. Some cases of chRCCs have features overlapping with ccRCCs in which the component cells have granular cytoplasm. In ccRCCs, at least some areas have cells with completely clear cytoplasm with high vascularity and typical, delicate, thin-walled, vascular structure throughout the tumour, contrasting with thick-walled blood vessels present in chRCCs. Also, a ccRCC lacks the plant-like architecture seen in chRCCs.

Table 1 describes the macroscopic and microscopic features of ROs and chRCCs. Despite having some subtle distinguishing macroscopic, microscopic and ultrastructural differences, there is often need to use ancillary histochemical and immunohistochemical (IHC) stains to differentiate these two entities. Recently, a new oncocytic variant of a chRCC was described, that morphologically resembles RO, but has the biological characteristics of a chRCC. ${ }^{43}$ This further adds to the difficulties for pathologists to discern ROs from all these variants of chRCCs.

To date, none of the histochemical, IHC or cytogenetic features has been proven to be reliable and specific. ${ }^{44}$ However, IHC markers may be a cost-effective and valuable form of information for monitoring disease for both prognosis and treatment-planning regimens. Tables 2-4 list some of the histochemical and IHC markers that have been published. Hale's colloidal iron staining is still used. Currently, the most useful IHC markers for the differentiation of renal tumours are vimentin, cytokeratin (CK)7, CD10 and marker for RCC (RCCma). Vimentin has been shown to be positive in ccRCCs and negative in chRCCs and ROs, and CK7 is positive in chRCCs and negative in ROs and ccRCCs. RCCma and CD10 are positive in ccRCCs and negative in both chRCCs and ROs. Hale's colloidal iron staining with diffuse reticular pattern and perinuclear halo is present in chRCCs but non-existent in ROs and ccRCCs. ${ }^{45}$

Table 4 Biomarkers from the cadherin family (also known as calcium-dependent adhesion)

\begin{tabular}{|c|c|c|c|}
\hline Method & Number of patients & Significance of success as biomarker & Ref \\
\hline $\begin{array}{l}\text { Kidney-specific cadherin } \\
\text { (Ksp-cad) }\end{array}$ & $\begin{array}{l}102 \text { ccRCC, } 46 \text { pRCC, } 30 \text { chRCC, } 3 \text { cdRCC, } \\
31 \text { RO } \\
42 \text { ccRCC, } 30 \text { pRCC, } 13 \text { chRCC, } 20 \text { RO using } \\
\text { whole sections } \\
15 \text { chRCC, } 15 \text { RO for mRNA analysis and IHC } \\
\text { on TMAs containing } 36 \text { chRCC, } 41 \text { RO }\end{array}$ & $\begin{array}{l}\text { Ksp-cad was expressed almost exclusively in chRCCs ( } 97.7 \% \text { of cases). Ksp-cad offers a } \\
\text { quick, dependable approach for differentiating between RO and chRCCs. } \\
\text { By contrast with Mazal et al, 2004, here both chRCC (13/13) and RO (19/20) were positive } \\
\text { for Ksp-cad. Ksp-cad not a useful marker for differentiating. } \\
\text { Ksp-cad differentiate RO from chRCC. Ksp-cad was present in chRCCs and ROs at mRNA } \\
\text { ( } 89 \% \text { chRCC and 64\% RO) and IHC ( } 31 / 36 \text { chRCCs and } 31 / 41 \text { RO) }\end{array}$ & 67 \\
\hline $\begin{array}{l}\mathrm{N} \text {-Cadherin } \\
\mathrm{E} \text {-Cadherin }\end{array}$ & 21 Japanese cases chRCC, ccRCC, RO. & $\begin{array}{l}\text { chRCC and RO were positive for E-cadherin but not for N-cadherin. All ccRCCs were } \\
\text { negative for E-cadherin, and } 58 \% \text { were positive for } \mathrm{N} \text {-cadherin. Useful to distinguish } \\
\text { chRCC from ccRCC but not between chRCC and RO. }\end{array}$ & 69 \\
\hline $\begin{array}{l}\text { Ep-CAM (epithelial cell } \\
\text { adhesion molecule) }\end{array}$ & 10 each of ccRCC, pRCC, chRCCs, RO & $\begin{array}{l}\text { Expressed in all chRCC in more than } 90 \% \text { of cells. EpCAM-positive RO }(5 / 17 ; 29 \%) \text { had } \\
\text { single cell or small cell cluster positivity. The homogeneous EpCAM expression assists to } \\
\text { diagnosis chRCC from RO. } \\
\text { EpCAM distinguished between RO and chRCC. RO were negative for EpCAM but positive } \\
\text { in } 8 / 10(80 \%) \text { of chRCC. }\end{array}$ & 47 \\
\hline
\end{tabular}

ccRCC, clear cell renal cell carcinoma; pRCC, papillary renal cell carcinoma; chRCC, chromophobe renal cell carcinoma; RO, renal oncocytoma; cdRCC, collecting duct renal cell carcinoma. 
Table 5 Biomarkers from the cytokeratin family

\begin{tabular}{|c|c|c|c|}
\hline Method & Number of patients & Significance of success as biomarker & Reference \\
\hline \multirow[t]{9}{*}{$\begin{array}{l}\text { CK7 (Basic or neutral } \\
\text { cytokeratin) }\end{array}$} & $6 \mathrm{chRCC}, 11 \mathrm{RO}$ & $\begin{array}{l}\text { All chRCC, strong cytoplasmic staining with peripheral cell accentuation. 8/11 RO, } \\
\text { negative, } 3 \text { weakly staining. }\end{array}$ & 70 \\
\hline & $21 \mathrm{chRCC}, 26 \mathrm{RO}$ & chRCCs $(100 \%)$ and almost all RO $(96 \%)$ were positive for CK7. & 71 \\
\hline & 11 chRCC, 21 RO from 4 hospitals & $\begin{array}{l}73 \% \text { chRCC, } 25 \% \text { RO positive for CK7; 33\% RO focally positive for CK7. No consistency } \\
\text { in differentiating the } 2 \text { neoplasms. }\end{array}$ & 72 \\
\hline & & Positive in $100 \%$ chRCC, $8 \%$ cCRCC and negative in RO. & 45 \\
\hline & $22 \mathrm{chRCC}, 17 \mathrm{RO}, 45 \mathrm{ccRCC}$ & Positive in $80 \%$ chRCC, $0 \%$ RO. & 47 \\
\hline & TMAs (20 each ccRCC, chRCC, pRCC, RO) & Positive in pRCC $(90 \%)$, chRCC $(89 \%)$, and RO $(90 \%)$. & 48 \\
\hline & TMAs (36 chRCC, 20 RO) & $\begin{array}{l}\text { Expressed significantly more often in chRCC than RO, both diffusely ( } 53 \% \text { vs } 10 \%) \text { and } \\
\text { focally ( } 42 \% \text { vs } 15 \%) \text {. }\end{array}$ & 48 \\
\hline & $\begin{array}{l}\text { TMAs ( } 30 \text { RO, } 18 \text { chRCC, } 64 \text { ccRCC, } 50 \\
\text { pRCC) }\end{array}$ & $81 \%$ pRCC, $63 \%$ chRCC, essentially negative in cCRCC and RO & 60 \\
\hline & 10 each $c \mathrm{RCC}$, pRCC, chRCC, RO & Distinguished RO and chRCC. RO were not stained $80 \%$ chRCCs were positive. & 64 \\
\hline $\begin{array}{l}\text { CK8 (Basic or neutral } \\
\text { cytokeratins) }\end{array}$ & $\begin{array}{l}76 \text { cases ( } 30 \text { ccRCC, } 16 \text { pRCC, } 21 \text { chRCC, } \\
8 \text { RO, } 1 \text { cdRCC) }\end{array}$ & Positive in $70 \%$ ccRCC, $93 \%$ chRCC and $87.5 \%$ RO. & 45 \\
\hline CK18 (Acidic cytokeratin) & $\begin{array}{l}76 \text { cases ( } 30 \text { ccRCC, } 16 \text { pRCC, } 21 \text { chRCC, } \\
8 \text { RO, } 1 \text { cdRCC) }\end{array}$ & Positive in $87 \%$ ccRCC, $100 \%$ chRCC and $87.5 \%$ RO. & 45 \\
\hline CK19 (Acidic cytokeratin) & $\begin{array}{l}76 \text { cases ( } 30 \text { ccRCC, } 16 \text { pRCC, } 21 \text { chRCC, } \\
8 \text { RO, } 1 \text { cdc) }\end{array}$ & $\begin{array}{l}\text { Positive in } 41 \% \text { ccRCC, } 37.5 \% \text { chRCC and } 62.5 \% \text { RO. Not a useful marker for } \\
\text { differentiation among these subtypes. }\end{array}$ & 45 \\
\hline \multirow[t]{3}{*}{ CK20 (Acidic cytokeratin) } & 15 RO only from archives & 12/15 RO were positive for CK20 & 73 \\
\hline & 11 chRCC, 21 RO from 4 hospitals & chRCC and RO were uniformly negative for CK20 & 72 \\
\hline & $\begin{array}{l}76 \text { cases ( } 30 \text { ccRCC, } 16 \text { pRCC, } 21 \text { chRCC, } \\
8 \text { RO, } 1 \text { cdRCC) }\end{array}$ & $\begin{array}{l}\text { Positive in only } 8 \% \text { ccRCCs, } 12.5 \% \text { chRCCs, negative in RO. Not a useful marker for } \\
\text { differentiation among these subtypes. }\end{array}$ & 45 \\
\hline
\end{tabular}

cCRCC, clear cell renal cell carcinoma; cdRCC, collecting duct renal cell carcinoma; chRCC, chromophobe renal cell carcinoma; pRCC, papillary renal cell carcinoma; RO, renal oncocytoma; TMA, tissue microarray.

Colloidal iron and widespread CK7 positivity have been suggested to be useful in distinguishing chRCCs from ROs. In ROs, colloidal iron staining is usually negative and CK7 shows only focal positivity. However, there is overlap in the staining patterns, preventing these stains to be of much practical value. Negative staining for vimentin and widespread staining for CK7 versus negative staining for CK7 and positive staining for vimentin can be useful in distinguishing chRCCs from ccRCCs.

However, as seen in table 2, these IHC markers still have their pitfalls in distinguishing between chRCCs and ROs. For example, the problems with Hale's colloidal iron in certain instances is its failure to stain adequately, or the staining pattern (diffuse cytoplasmic vs luminal) could not be adequately assessed. ${ }^{46}$ However, vimentin may be useful in discriminating chRCCs from other RCCs, and a panel of vimentin with GST- $\alpha$ and EpCAM may achieve 100\% sensitivity and specificity for the differential diagnosis of chRCCs, ROs and ccRCCs. ${ }^{47}$

ROs and chRCCs share histologic and cytologic features, and also share IHC markers for S100A1 and CD117 (KIT). ${ }^{48}$ Several other studies with IHC markers, including kidneyspecific cadherin, CK7, EMA, CD10, RCC, c-KIT, and RON proto-oncogene have been used to distinguish chRCCs from ROs, but the results of these studies are inconsistent and unsatisfactory. ${ }^{49}$ Table 3 illustrates current biomarkers used to differentiate chRCCs from ROs, directly or indirectly. BCA2, a RING $\mathrm{H} 2$ finger protein RING E3 ligase, holds potential as a tool to distinguish ROs from its mimickers, like chRCCs. ${ }^{50}$ Additionally, RO has significantly higher expression of the cancer-testis antigens (CTAs), such as MAGE-A3/4 and NY-ESO-1. ${ }^{51}$ Further investigation is needed to evaluate the potential diagnostic implications for these markers.

The cadherins comprise of a family of transmembrane glycoproteins that function as calcium-dependent homotypic adhesion molecules and are expressed by the majority of epithelium. Currently, over 20 different tissue-specific cadherins have been identified. ${ }^{52}$ The promise of cadherin proteins in distinguishing chRCCs from ROs is shown in table 4. CKs are a family of intermediate filaments that are characteristic markers of epithelial differentiation. Currently, 20 distinct CKs have been identified. They can be useful in the differential diagnosis of neoplasms of epithelial origin, and consequently, several CKs been investigated in renal neoplasms. ${ }^{53}$ The CKs that have been trialled to discriminate chRCCs from other RCCs and also ROs, are listed in table 5 , but none holds major promise, including CK7. Caveolin-1 is a scaffolding protein encoded by the Cav-1 protein. This has demonstrated better promise in differentiating chRCCs from ROs than CK7. ${ }^{47}$

\section{CONCLUSION}

The standard treatment of localised renal tumours remains surgical resection via complete or partial nephrectomy. The increasing detection of small renal masses with a significant chance of benign aetiology provides a diagnostic and management challenge. ROs, and to a lesser extent small chRCCs, are two lesions that could be managed conservatively in many situations, avoiding the morbidity inherent to resection of renal lesions. However, a very high level of diagnostic certainty is required if surgical intervention is to be avoided. Current imaging and biopsy techniques do not always provide this certainty as evidenced by the number of benign small renal lesions reported in contemporary surgical series. If confident diagnosis of renal lesions with low or no malignant potential can be achieved, then active surveillance will usually be appropriate, with intervention reserved for tumours demonstrating excessive growth or symptoms. The ability to diagnose ROs and chRCCs with a high level of confidence may lead to improved use of preoperative diagnostic techniques and reduced intervention rates for indolent renal lesions. Achieving consistent accurate diagnosis of ROs and chRCCs via non-surgical means will remain elusive until modern molecular biomarkers are identified. 
Key messages

- Clinical diagnostic dilemma and difficult histopathological differentiation of renal oncocytoma from chromophobe renal cell carcinoma still persist.

- The ability to achieve confident accurate diagnosis of these renal tumors via non-surgical means remain elusive until new specific molecular biomarkers are discovered.

- Better preoperative non-invasive characterisation of specific biomarkers for renal oncocytoma and chromophobe renal cell carcinoma may lead to reduced rates of surgical intervention for benign renal lesions.

Contributors KLN, RR and YNY performed the literature search. KLN, RR, YNY, HS and CM drafted the manuscript, while GCG and STW helped in the critical revision of the manuscript. HS provided the picture of histology slides. All authors contributed actively in this manuscript, and all approved the final revised version of this manuscript.

Funding This review article was partly supported by the University Malaya Research Grant (UMRG RG348/11HTM).

Competing interests None.

Provenance and peer review Not commissioned; externally peer reviewed.

\section{REFERENCES}

1 Ljungberg B, Campbell SC, Choi HY, et al. The epidemiology of renal cell carcinoma. Eur Urol 2011;60:615-21.

2 Duchene DA, Lotan Y, Cadeddu JA, et al. Histopathology of surgically managed renal tumors: analysis of a contemporary series. Urology 2003;62:827-30.

3 Gupta K, Miller JD, Li JZ, et al. Epidemiologic and socioeconomic burden of metastatic renal cell carcinoma (mRCC): a literature review. Cancer Treat Rev 2008:34:193-205.

4 Schachter LR, Cookson MS, Chang SS, et al. Second prize: frequency of benign renal cortical tumors and histologic subtypes based on size in a contemporary series: what to tell our patients. J Endourol 2007:21:819-23.

5 Yusenko MV. Molecular pathology of renal oncocytoma: A review. Int J Urol 2010;17:602-12.

6 Oxley JD, Sullivan J, Mitchelmore A, et al. Metastatic renal oncocytoma. J Clin Pathol 2007:60:720-2.

7 Delongchamps NB, Galmiche L, Eiss D, et al. Hybrid tumour 'oncocytomachromophobe renal cell carcinoma' of the kidney: a report of seven sporadic cases. BJU Int 2009;103:1381-4.

8 Zippel . Zur Kenntnis der Oncocytome. Virchows Arch A Pathol Anat 1942:308:360-82.

9 Klein MJ, Valensi QJ. Proximal tubular adenomas of kidney with so-called oncocytic features. A clinicopathologic study of 13 cases of a rarely reported neoplasm. Cancer 1976;38:906-14.

10 Storkel S, Pannen B, Thoenes W, et al. Intercalated cells as a probable source for the development of renal oncocytoma. Virchows Arch B Cell Pathol Incl Mol Pathol 1988:56:185-9.

11 Thoenes W, Storkel S, Rumpelt HJ. Human chromophobe cell renal carcinoma. Virchows Arch B Cell Pathol Ind Mol Pathol 1985:48:207-17.

12 Thoenes W. SSaRHJ. Histopathology and classification of renal cell tumours (adenomas, oncoccytomas, carcinomas). The basic cytological amd histopathological elements and their use for diagnostics. Pathol Res Pract 1986;181:125-43.

13 Amin R, Anthony P. Metastatic renal oncocytoma: A case report and review of the literature. Clin Oncol (R Coll Radiol) 1999;11:277-9.

14 Chawla SN, Crispen PL, Hanlon AL, et al. The natural history of observed enhancing renal masses: meta-analysis and review of the world literature. J Urol 2006; 175:425-31.

15 Kawaguchi S, Fernandes KA, Finelli A, et al. Most renal oncocytomas appear to grow: observations of tumor kinetics with active surveillance. $J$ Urol 2011:186:1218-22

16 Kurup AN, Thompson RH, Leibovich BC, et al. Renal oncocytoma growth rates before intervention. BJU Int 2012;110:1444-8.

17 Cindolo L, de ITA, Schips L, et al. Chromophobe renal cell carcinoma: comprehensive analysis of 104 cases from multicenter European database. Urology 2005;65:681-6.

18 Vera-Badillo FE, Conde E, Duran I. Chromophobe renal cell carcinoma: a review of an uncommon entity. Int J Urol 2012:19:894-900.
19 Lopez-Beltran A, Scarpelli M, Montironi R, et al. 2004 WHO classification of the renal tumors of the adults. Eur Urol 2006;49:798-805.

20 Khoo SK, Bradley M, Wong FK, et al. Birt-Hogg-Dube syndrome: mapping of a novel hereditary neoplasia gene to chromosome 17p12-q11.2. Oncogene 2001:20:5239-42.

21 Nickerson ML, Warren MB, Toro JR, et al. Mutations in a novel gene lead to kidney tumors, lung wall defects, and benign tumors of the hair follicle in patients with the Birt-Hogg-Dube syndrome. Cancer cell 2002;2:157-64.

22 Warfel KA, Eble JN. Renal oncocytomatosis. J Urol 1982;127:1179-80.

23 Adamy A, Lowrance WT, Yee DS, et al. Renal oncocytosis: management and clinical outcomes. J Urol 2011;185:795-801.

24 Volpe A, Novara G, Antonelli A, et al. Chromophobe renal cell carcinoma (RCC): oncological outcomes and prognostic factors in a large multicentre series. BJU Int 2012;110:76-83.

25 Tobias Klatte K-rH, Jonathan W. Said, Malte Bohm. Pathobiology and prognosis of chromophobe renal cell carcinoma. Urol Oncol-Semin Orig Investig 2008:26:604-09.

26 PerezOrdonez B, Hamed G, Campbell S, et al. Renal oncocytoma: A clinicopathologic study of 70 cases. Am J Surg Pathol 1997;21:871-83.

27 Akbulut S, Senol A, Cakabay B, et al. Giant renal oncocytoma: a case report and review of the literature. J Med Case Rep 2010:4:52.

28 Romis L, Cindolo L, Patard JJ, et al. Frequency, clinical presentation and evolution of renal oncocytomas: multicentric experience from a European database. Eur Urol 2004;45:53-7; discussion 57

29 Dechet CB, Bostwick DG, Blute MJ, et al. Renal oncocytoma: Multifocality, bilateralism, metachronous tumor development and coexistent renal cell carcinoma. J Urology 1999;162:40-2.

30 Trpkov K, Yilmaz A, Uzer D, et al. Renal oncocytoma revisited: a clinicopathological study of 109 cases with emphasis on problematic diagnostic features. Histopathology 2010;57:893-906.

31 Davis CJ MF, Sesterhenn IA, Ho CK. Renal Oncocytoma. Clinicopathological study of 166 patients. J Urogenital Pathol 1991:1:41-52.

32 Cheville JC, Lohse CM, Zincke $\mathrm{H}$, et al. Comparisons of outcome and prognostic features among histologic subtypes of renal cell carcinoma. Am I Surg Pathol 2003;27:612-24

33 Yusenko MV. Molecular pathology of chromophobe renal cell carcinoma: a review. Int J Urol 2010;17:592-600.

$34 \mathrm{Kim} \mathrm{JK}$, Kim TK, Ahn HJ, et al. Differentiation of subtypes of renal cell carcinoma on helical CT scans. AJR Am J Roentgenol 2002;178:1499-506.

35 Remark RR, Berquist TH, Lieber MM, et al. Magnetic resonance imaging of renal oncocytoma. Urology 1988;31:176-9.

36 Choudhary S, Rajesh A, Mayer NJ, et al. Renal oncocytoma: CT features cannot reliably distinguish oncocytoma from other renal neoplasms. Clin Radiol 2009;64:517-22

37 Rosenkrantz $A B$, Hindman N, Fitzgerald $E F$, et al. MRI features of renal oncocytoma and chromophobe renal cell carcinoma. AJR Am J Roentgenol 2010;195:W421-7.

38 Aide $\mathrm{N}$, Cappele $\mathrm{O}$, Bottet $\mathrm{P}$, et al. Efficiency of [(18)F]FDG PET in characterising renal cancer and detecting distant metastases: a comparison with CT. Eur J NuCl Med Mol Imaging 2003;30:1236-45.

39 Ramdave S, Thomas GW, Berlangieri SU, et al. Clinical role of F-18 fluorodeoxyglucose positron emission tomography for detection and management of renal cell carcinoma. J Urol 2001;166:825-30.

40 Young JR, Margolis D, Sauk S, et al. Clear Cell Renal Cell Carcinoma: Discrimination from Other Renal Cell Carcinoma Subtypes and Oncocytoma at Multiphasic Multidetector CT. Radiology 2013;267:444-53.

41 Bird VG, Kanagarajah P, Morillo G, et al. Response by authors re: Differentiation of oncocytoma and renal cell carcinoma in small renal masses $(<4 \mathrm{~cm})$ : the role of 4-phase computerized tomography. World I Urol 2013;31:1011-2.

42 Barocas DA, Rohan SM, Kao J, et al. Diagnosis of renal tumors on needle biopsy specimens by histological and molecular analysis. J Urol 2006;176:1957-62.

43 Kuroda N, Tanaka A, Yamaguchi T, et al. Chromophobe renal cell carcinoma, oncocytic variant: a proposal of a new variant giving a critical diagnostic pitfall in diagnosing renal oncocytic tumors. Med Mol Morphol 2013;46:49-55.

44 Mazal PR, Exner M, Haitel A, et al. Expression of kidney-specific cadherin distinguishes chromophobe renal cell carcinoma from renal oncocytoma. Human pathology 2005;36:22-8.

45 Geramizadeh B, Ravanshad M, Rahsaz M. Useful markers for differential diagnosis of oncocytoma, chromophobe renal cell carcinoma and conventional renal cell carcinoma. Indian J Pathol Microbiol 2008:51:167-71.

46 Latham B, Dickersin GR, Oliva E. Subtypes of chromophobe cell renal carcinoma: an ultrastructural and histochemical study of 13 cases. Am I Surg Pathol 1999:23:530-5

47 Liu L, Qian J, Singh H, et al. Immunohistochemical analysis of chromophobe renal cell carcinoma, renal oncocytoma, and clear cell carcinoma: an optimal and practical panel for differential diagnosis. Arch Pathol Lab Med 2007;131:1290-7.

48 Bing Z, Lal P, Lu S, et al. Role of carbonic anhydrase IX, alpha-methylacyl coenzyme a racemase, cytokeratin 7, and galectin-3 in the evaluation of renal neoplasms: a tissue microarray immunohistochemical study. Ann Diagn Pathol 2013;17:58-62. 
49 Lee HW, Lee EH, Lee CH, et al. Diagnostic Utility of Caveolin-1 and MOC-31 in Distinguishing Chromophobe Renal Cell Carcinoma from Renal Oncocytoma. Korean J Urol 2011;52:96-103.

50 Ehsani L, Seth R, Bacopulos S, et al. BCA2 is differentially expressed in renal oncocytoma: an analysis of 158 renal neoplasms. Tumour Biol 2013; 34:787-91.

51 Demirovic A, Dzombeta T, Tomas D, et al. Immunohistochemical expression of tumor antigens MAGE-A3/4 and NY-ESO-1 in renal oncocytoma and chromophobe renal cell carcinoma. Pathol Res Pract 2010;206:695-9.

52 Langner $C$, Ratschek M, Rehak P, et al. Expression of MUC1 (EMA) and E-cadherin in renal cell carcinoma: a systematic immunohistochemical analysis of 188 cases. Mod Pathol 2004:17:180-8.

53 Skinnider BF, Folpe AL, Hennigar RA, et al. Distribution of cytokeratins and vimentin in adult renal neoplasms and normal renal tissue: potential utility of a cytokeratin antibody panel in the differential diagnosis of renal tumors. Am J Surg Pathol 2005;29:747-54.

54 Gudbjartsson T, Hardarson S, Petursdottir V, et al. Renal oncocytoma: a clinicopathological analysis of 45 consecutive cases. BJU Int 2005;96:1275-9.

55 Tickoo SK, Amin MB. Discriminant nuclear features of renal oncocytoma and chromophobe renal cell carcinoma. Analysis of their potential utility in the differential diagnosis. Am J Clin Pathol 1998;110:782-7.

56 Abrahams NA, MacLennan GT, Khoury JD, et al. Chromophobe renal cell carcinoma: a comparative study of histological, immunohistochemical and ultrastructural features using high throughput tissue microarray. Histopathology 2004;45:593-602.

57 Crotty TB, Farrow GM, Lieber MM. Chromophobe cell renal carcinoma: clinicopathological features of 50 cases. J Urol 1995;154:964-7.

58 Wang HY, Mills SE. KIT and RCC are useful in distinguishing chromophobe renal cell carcinoma from the granular variant of clear cell renal cell carcinoma. Am J Surg Pathol 2005;29:640-6.

59 Tickoo SK, Amin MB, Zarbo RJ. Colloidal iron staining in renal epithelial neoplasms, including chromophobe renal cell carcinoma: emphasis on technique and patterns of staining. Am J Surg Pathol 1998;22:419-24.

60 Huang W, Kanehira K, Drew S, et al. Oncocytoma can be differentiated from its renal cell carcinoma mimics by a panel of markers: an automated tissue microarray study. Appl Immunohistochem Mol Morphol 2009;17:12-7.
61 Pan CC, Chen PC, Ho DM. The diagnostic utility of MOC31, BerEP4, RCC marker and CD10 in the classification of renal cell carcinoma and renal oncocytoma: an immunohistochemical analysis of 328 cases. Histopathology 2004;45:452-9.

62 Huo L, Sugimura J, Tretiakova MS, et al. C-kit expression in renal oncocytomas and chromophobe renal cell carcinomas. Hum Pathol 2005;36:262-8.

63 Pan CC, Chen PC, Chiang H. Overexpression of KIT (CD117) in chromophobe renal cell carcinoma and renal oncocytoma. Am J Clin Pathol 2004;121:878-83.

64 Ray ER, Goodwill J, Chandra A, et al. Exploring the Potential of Immunohistochemistry to Identify Renal Oncocytoma. Br J Med Surg Urol 2011;4:8-12.

65 Patton KT, Tretiakova MS, Yao JL, et al. Expression of RON Proto-oncogene in Renal Oncocytoma and Chromophobe Renal Cell Carcinoma. Am I Surg Pathol 2004:28:1045-50.

66 Brunelli M, Delahunt B, Gobbo S, et al. Diagnostic usefulness of fluorescent cytogenetics in differentiating chromophobe renal cell carcinoma from renal oncocytoma: a validation study combining metaphase and interphase analyses. $\mathrm{Am}$ J Clin Pathol 2010;133:116-26.

67 Shen SS, Krishna B, Chirala R, et al. Kidney-specific cadherin, a specific marker for the distal portion of the nephron and related renal neoplasms. Mod Pathol 2005;18:933-40.

68 Adley BP, Gupta A, Lin F, et al. Expression of kidney-specific cadherin in chromophobe renal cell carcinoma and renal oncocytoma. Am J Clin Pathol 2006;126:79-85

69 Taki A, Nakatani Y, Misugi K, et al. Chromophobe renal cell carcinoma: an immunohistochemical study of 21 Japanese cases. Mod Pathol 1999;12:310-7.

70 Leroy X, Moukassa D, Copin MC, et al. Utility of cytokeratin 7 for distinguishing chromophobe renal cell carcinoma from renal oncocytoma. Eur Urol 2000;37:484-7.

71 Garcia E, Li M. Caveolin-1 immunohistochemical analysis in differentiating chromophobe renal cell carcinoma from renal oncocytoma. Am J Clin Pathol 2006:125:392-8.

72 Wu SL, Kothari P, Wheeler TM, et al. Cytokeratins 7 and 20 immunoreactivity in chromophobe renal cell carcinomas and renal oncocytomas. Mod Pathol 2002;15:712-7.

73 Stopyra GA, Warhol MJ, Multhaupt HA. Cytokeratin 20 immunoreactivity in renal oncocytomas. J Histochem Cytochem 2001;49:919-20. 